This item was submitted to Loughborough's Research Repository by the author.

Items in Figshare are protected by copyright, with all rights reserved, unless otherwise indicated.

\title{
A domestic demand model for India
}

PLEASE CITE THE PUBLISHED VERSION

https://doi.org/10.1007/978-981-15-2666-4_70

PUBLISHER

Springer

VERSION

AM (Accepted Manuscript)

PUBLISHER STATEMENT

The final authenticated publication is available online at https://doi.org/10.1007/978-981-15-2666-4_70.

\section{LICENCE}

CC BY-NC-ND 4.0

\section{REPOSITORY RECORD}

Barton, John, Murray Thomson, Philip Sandwell, and Alexander Mellor. 2020. "A Domestic Demand Model for India". Loughborough University. https://hdl.handle.net/2134/33815. 


\title{
A Domestic Demand Model for India
}

\author{
John Barton ${ }^{1[0000-0002-1880-6833]}$, Murray Thomson ${ }^{10000-0001-6434-1478]}$, Philip Sandwell ${ }^{\text {[0000-0003-1117-5095] }}$, Alexander \\ Mellor 2 [0000-0003-2360-0861]
}

\author{
${ }^{1}$ Loughborough University, Loughborough LE11 3TU, UK \\ ${ }^{2}$ Imperial College, Kensington, London SW7 2AZ \\ lncs@springer.com
}

\begin{abstract}
This paper describes the extension of CREST's popular and open-source domestic energy demand model for UK households into one that can also model households in India. The model is based on a representation of individual appliances and their usage, dependent on 'active occupancy', meaning the times that people are both at home and awake. The model is well suited to the analysis of low-voltage networks and micro-grids, for which its ability to account for demand diversity is of critical importance.

Energy consumption in households in India is quite different from that in the UK. Several functional extensions are required in order to represent features that are significant in India.

The per-household ownership of appliances and lighting fixtures is currently much lower in India than in the UK. The model represents both urban and rural locations, and the expected increase in appliance ownership in India. In India, the model shows that domestic demand profile is currently more heavily dominated by an evening peak of demand.
\end{abstract}

Keywords: Domestic, Energy use, Thermal demand, Energy demand model, High-resolution.

\section{Introduction to the Domestic Demand Model}

\subsection{The role of demand models with high temporal resolution}

Stochastic energy demand models enable the examination of very localized and temporal effects that are not captured by whole-system top-down models. They are useful because diversity is critical in local distribution networks.

On the one hand, the lack of diversity could overload the network. For example, the output of solar photovoltaic (PV) power, demand of air conditioning or concentrations of one technology (e.g. electric vehicle charging) could create peaks of generation or peaks of demand throughout the network. On the other hand, the diversity of appliance use is helpful. Aggregated over the whole network, the diversity of use enables the peaks of demand from individual appliances to be absorbed and accommodated. Good temporal resolution is critical to the modelling of battery cycling in micro-grids, where individual appliances constitute a large fraction of the total system demand.

Models that create synthetic demand data are useful because real demand data is hard to obtain, partly because the recording of demand data presents privacy issues for the households or businesses concerned.

\subsection{Introduction to the Demand Model}

This paper describes the extension of CREST's open-source domestic energy demand model for UK households [1-4] into one that can also model households in India [5,6]. The model is based on a representation of individual appliances and their usage, dependent on 'active occupancy', meaning the times that people are both at home and awake. The time resolution of the model is one minute, to capture the typical changes in demand resulting from appliance switching events.

Energy consumption in households in India is quite different from that in the UK and, whilst the established model architecture remains sound, a substantial overhaul of the underlying data is required. Moreover, several functional extensions are required in order to represent features that are significant in India but which were not included for the UK. The per-household ownership of appliances and lighting fixtures is currently much lower in India than in the UK, especially in rural locations. The new model, version 2.3, represents both urban and rural locations, and the expected increase in appliance ownership in India. 
The last version of the CREST demand model for the UK, version 2.2 [4] included a thermal model of the building fabric of the house and demand for heating. The model includes solar photovoltaic and solar thermal models, with solar irradiance data modified by longitude and latitude.

For India, the new model, version 2.3, also represents cooling technologies, which are increasingly being used. The model includes the ability to calculate their dependence on the local climate and season. Cooling equipment is almost entirely electrically driven and air conditioning has the potential to be the largest single consumer of electricity in Indian households.

The model remains an open-source development in Excel VBA and is freely available to download [5,6].

\section{Description of the Domestic Demand Model}

The structure of the Indian model is largely the same as the UK model, Fig. 1. The following factors are randomized in the creation of differences between households, and changes in demand from one minute to the next:

- Appliance ownership

- Ownership of heating and cooling technologies

- Number of people per household

- Waking, sleeping, leaving home and arriving at home

- Solar PV and solar thermal ownership

- Timer controls for heating or cooling

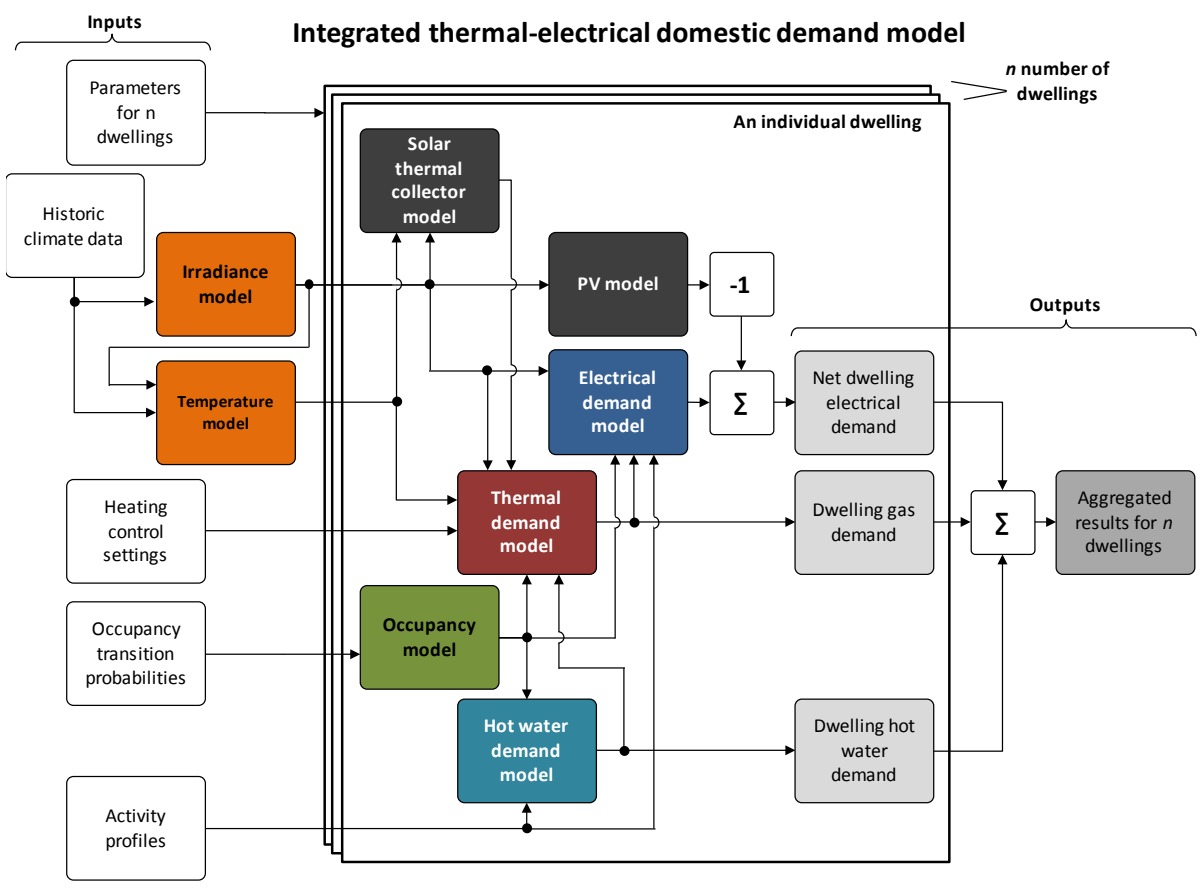

Fig. 1. Structure of the domestic demand model

The thermal demand model now models the requirement for cooling technologies when modelling Indian households. When modelling UK households, it still models heating requirements.

The demand from electrical appliances is calculated using a bottom-up model of appliance ownership and appliance use based on active occupancy. Example output for ten Indian households over a period of one day is shown in Fig. 2 before and after subtraction of solar photovoltaic power. It can be seen that in this particular example, the demand is dominated by air conditioning that creates a base-load demand of about 3.5kW. 


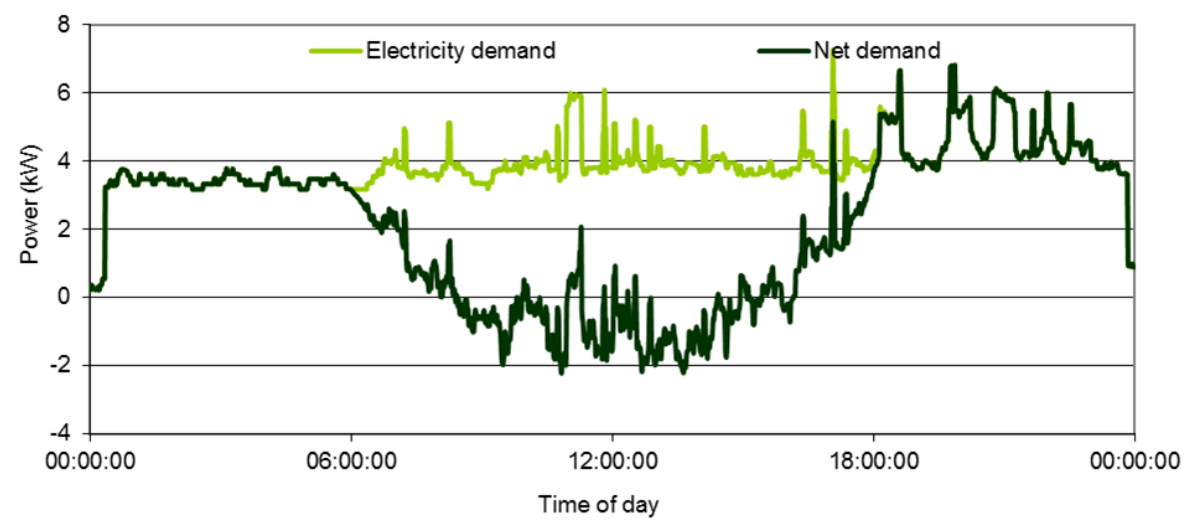

Fig. 2. Model output for 10 urban Indian households with air conditioning in year 2026

\subsection{Differences between the Indian and UK Models}

The present and predicted ownership of electrical appliances in India is substantially lower than in the UK, based on a World Bank Report [7]. Rural Indian households own fewer of each type of appliance than Urban households, and appliance ownership is growing over time until year 2031. Nevertheless, the total numbers are low compared to ownership in the UK in year 2000, Fig. 3.

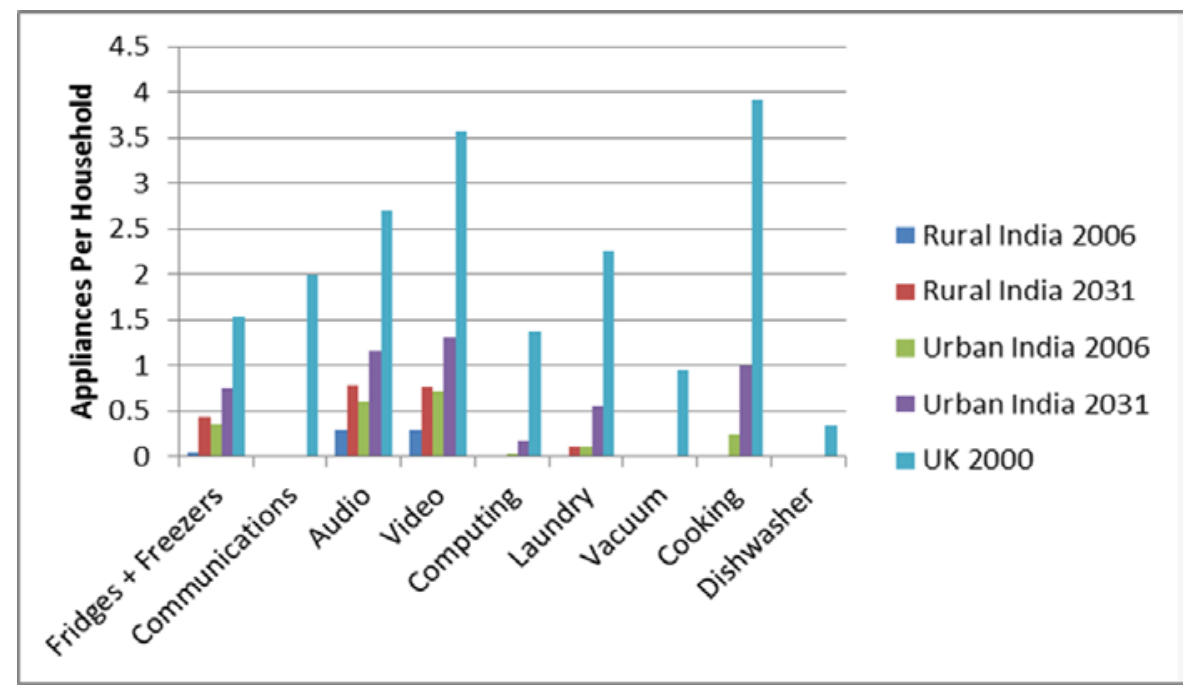

Fig. 3. Modelled projections of appliance ownership in India compared to the UK

The Indian version of the model includes a choice of six geographic locations around India for local temperature climate data. The Indian electricity transmission system consists of five grid management regions. The model provides at least one location within each region, Table 1. The Southern region contains both Chennai and Bengaluru to represent both a coastal and high elevation location respectively. England in the UK is included for completeness; the new demand model can still optionally model households in the UK.

Table 1. Locations of climate data available as options in the domestic demand model

\begin{tabular}{|l|l|l|}
\hline Location & Grid Region & Description of Climate \\
\hline
\end{tabular}




\begin{tabular}{|l|l|l|}
\hline N Delhi & Northern & Hot summer, cool winter \\
\hline Mumbai & Western & Hot summer, warm winter \\
\hline Bengaluru & Southern & Warm throughout the year \\
\hline Chennai & Southern & Hot summer, warm winter \\
\hline Kolkata & Eastern & Hot summer, warm winter \\
\hline Itanagar & North-Eastern & Warm summer, cool winter \\
\hline England & United Kingdom & Cool summer, cold winter \\
\hline
\end{tabular}

The monthly average temperatures for representative locations are shown in Fig. 4.

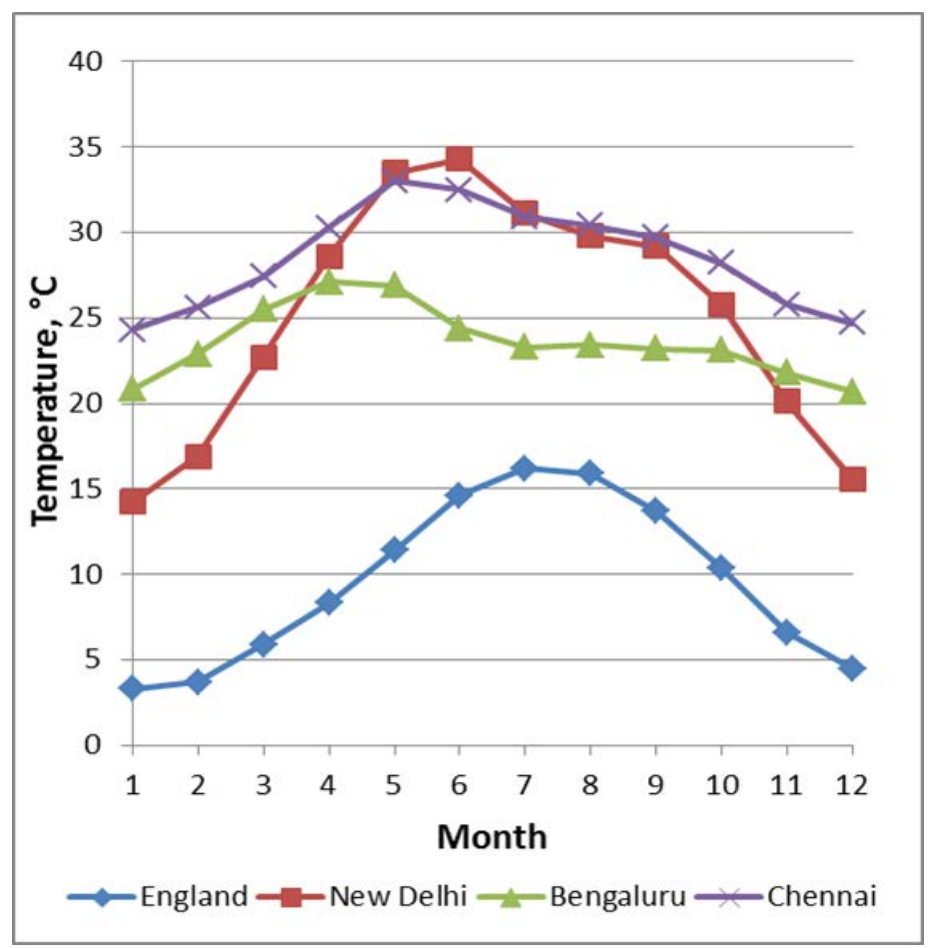

Fig. 4. Monthly average temperatures in a selection of modelled climate locations

The climate data chosen need not be geographically close to the actual modelled location but should merely be close in temperature. Longitude and latitude are direct inputs to the model to enable the modelling of any specific location in India (or the UK) for the purposes of calculating solar elevation and azimuthal angle.

Together with this longitude and latitude, the time zone meridian must be chosen to create a set of daily patterns of occupancy and activity, consistent with the solar elevation. The model is thus designed for future expansion to other countries but for the moment the options for meridian are $0^{\circ}$ for the UK and $82.5^{\circ}$ East for the Indian time zone.

The UK version of the model was designed for daylight saving time, or British Summer Time (BST), as different from Greenwich Mean Time (GMT) used in the UK in winter. Thus the UK is 4.5 hours behind India in summer (April to October), and 5.5 hours behind India in winter (November to March). This daylight saving option must be switched off when modelling Indian households.

The old, UK-only version of the user input control sheet, version 2.2 is shown in Fig. $\mathbf{5}$ and the new control sheet, version 2.3 is shown in Fig. 6, including all the new input options.

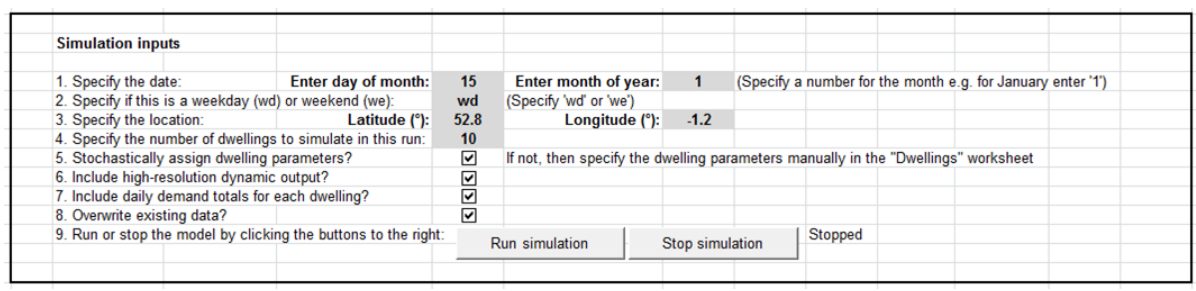


Fig. 5. Input control options on the main sheet of the previous version of the model, v2.2

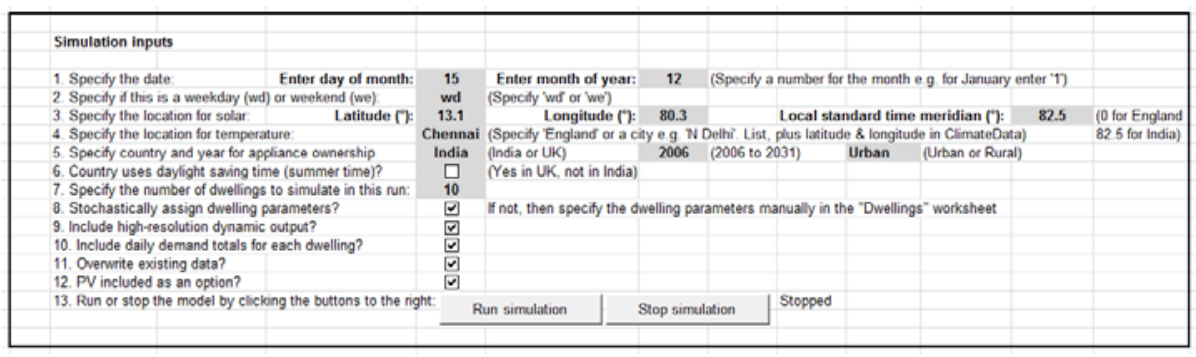

Fig. 6. Input control options on the main sheet of the present version of the model, v2.3

\subsection{Similarities between the Indian and UK Models}

When creating the Indian demand model, very little data on time-use in India was available. The data used was from a study conducted in un-electrified villages in Uttar Pradesh [8]. The activities of 553 people in 51 households were collected by interview and then averaged. Divided into seven categories, the daily activities are shown in Fig. 7.

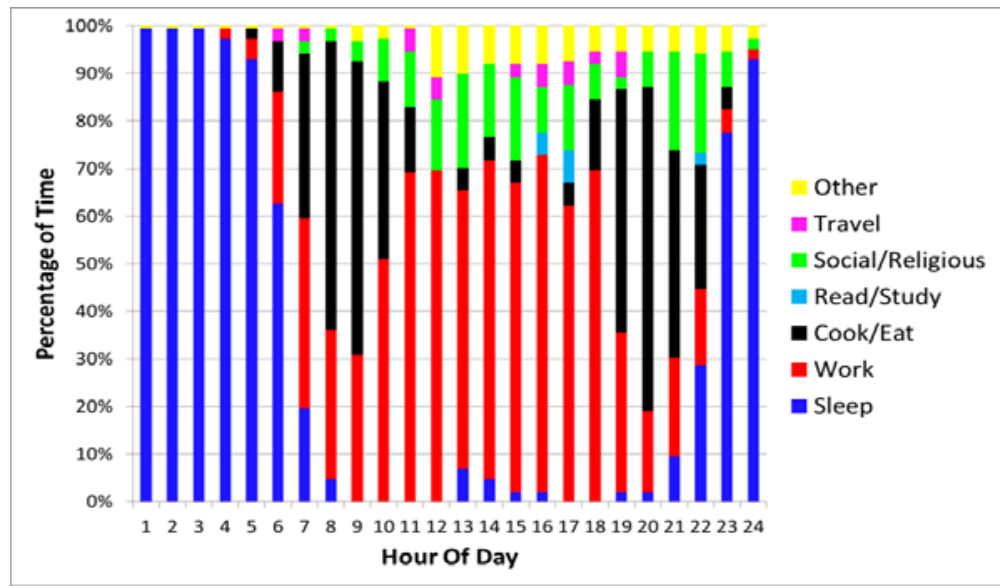

Fig. 7. Time use data for un-electrified villages in Uttar Pradesh

If some reasonable assumptions are made to divide these activities into 'home' or 'away', and into 'active' and 'inactive', Table 2, then the time-use survey can be converted into profiles of activity, occupancy and active-occupancy. The results of this exercise are plotted in Fig. 8, where Indian active-occupancy is compared with UK active-occupancy.

Table 2. Conversion of reported time use data into activity and occupancy

\begin{tabular}{|l|l|l|}
\hline Activity & Active? (Yes / No) & At Home? (Percentage) \\
\hline Sleep & No & $100 \%$ \\
\hline Work & Yes & $0 \%$ \\
\hline Cook / Eat & Yes & $75 \%$ \\
\hline Read / Study & Yes & $100 \%$ \\
\hline Social / Religious & Yes & $100 \%$ \\
\hline Travel & Yes & $0 \%$ \\
\hline Other & Yes & $100 \%$ \\
\hline
\end{tabular}

It can be seen in Fig. 8 that the differences between India and UK activity and occupancy profiles are small. India apparently spends a little less time active and at home than the UK. If anything, the calculation above may over-estimate active-occupancy in India, since the 'social and religious' and 'other' activities may take place outside the home, further reducing active occupancy. However, it must be remembered that this small time-use survey was conducted in un-electrified villages where evening lighting is scarce. Access to electricity may 
significantly increase active occupancy in these villages to a level much closer to the UK. The differences are small enough that it was not worth changing the active-occupancy model for the Indian version of the model.

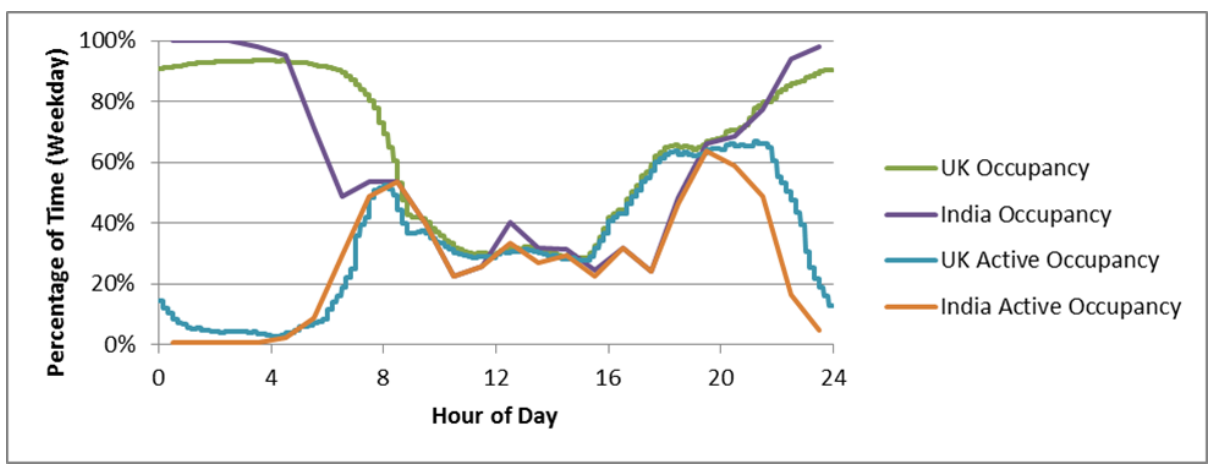

Fig. 8. Active occupancy of un-electrified villages of Uttar Pradesh compared to the UK

It is well known that average household size in India is much larger than in the UK. The average number of people living in each home is about 2 in the UK, compared to over 4 in India, with almost 5 people per household in rural India. In the UK active occupancy model, the probability of each appliance being used is related not only to appliance ownership, but also to the number of active-occupants in the house: Not only is it a requirement of appliance use that at least one person is active and at home, but an increase in the number of active occupants increases the probability that each appliance is used.

However, in the Indian context, no significant correlation is found between active occupancy and appliance use, Fig. 9, Fig. 10, Fig. 11, Fig. 12, based on a study of a minigrid in Uttar Pradesh [9] . If anything, the data suggests that larger households use each electrical appliance for slightly fewer hours per day.

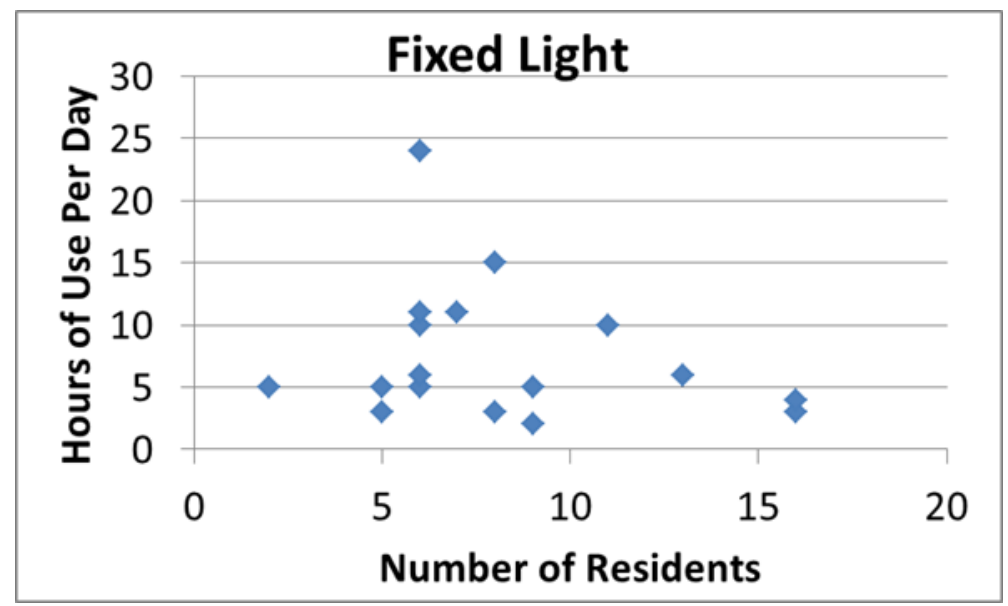

Fig. 9. Fixed light use vs. household size 


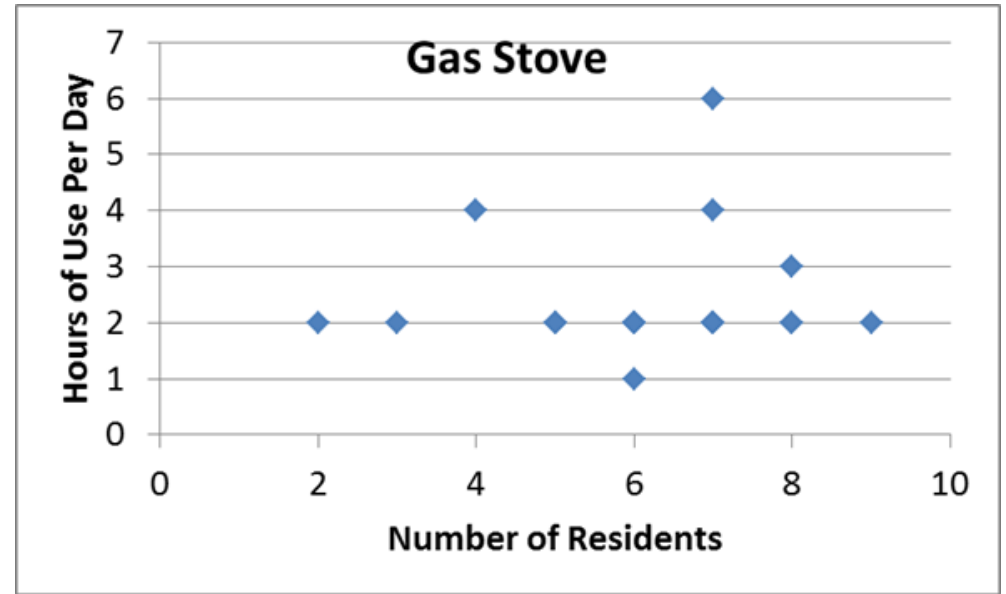

Fig. 10. Gas stove use vs. household size

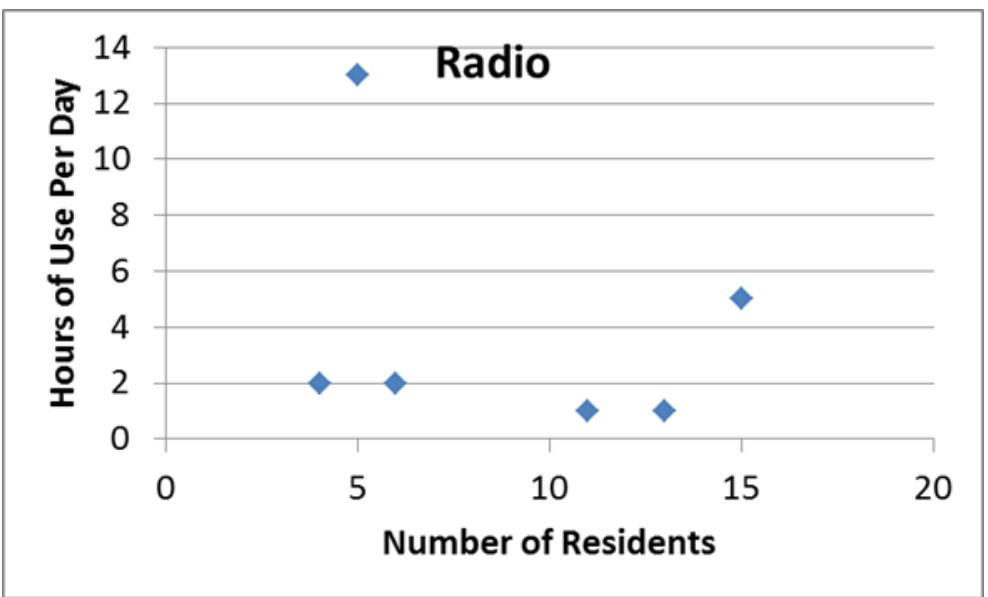

Fig. 11. Radio use vs. household size

This lack of correlation between number of occupants and appliance use meant that it was not worth changing the active-occupancy model from that of the UK version. The active-occupancy model therefore remains as it was, based on an average household size of about 2 .

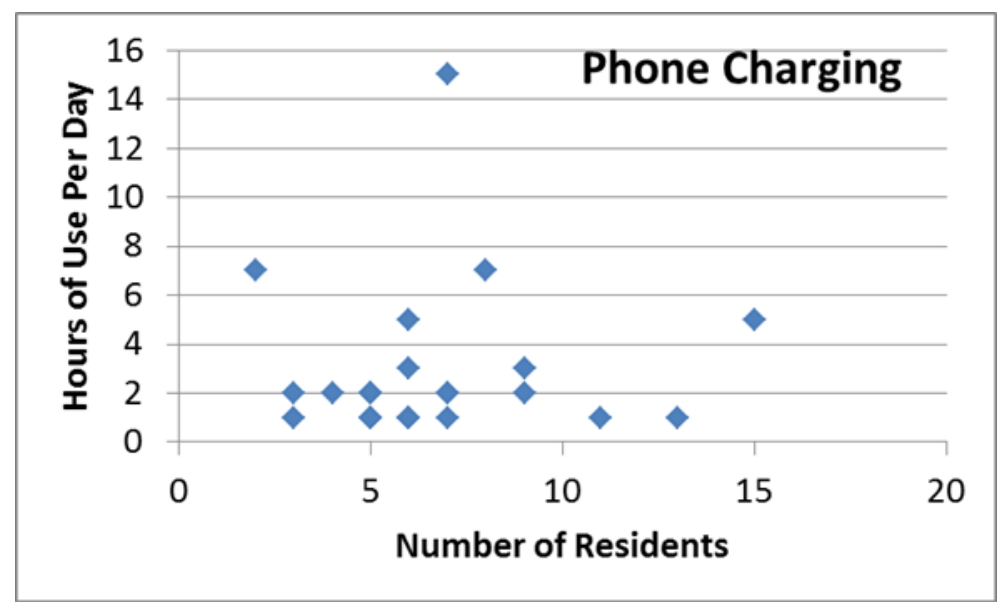

Fig. 12. Phone charging vs. household size 


\section{Results of the Indian Domestic Demand Model}

The results for 100 households without any cooling technologies are compared with UK demand model output in Fig. 13. Rural and urban households are modelled, and year 2006 is compared with 2031. In line with appliance ownership, and with some improvement to appliance efficiencies, total domestic electricity demand is predicted to remain much lower in India than in the UK in year 2000, at least until year 2031.

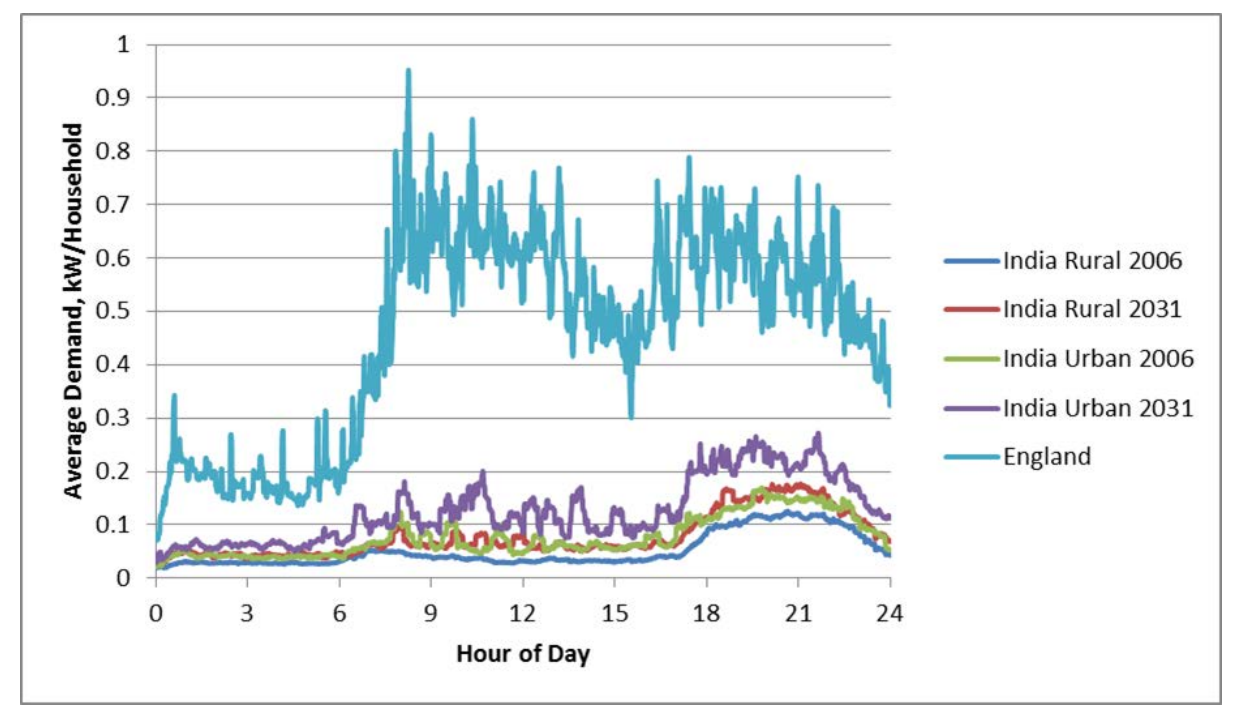

Fig. 13. Results of the India and UK models, each for 100 households, excluding space heating and cooling technologies

The profile of appliance use in India has a relatively large peak of electricity demand in the evening, Fig. 13 whereas the UK has a flatter demand profile and a peak earlier in the day.

When air conditioning is added in, Fig. 2, its electricity demand dominates total demand, but only a small fraction of Indian households have air conditioning, Table 3. A slightly larger percentage have evaporative coolers (swamp coolers) and a large proportion of electrified households use ceiling fans, but these other technologies use much less electricity than full air conditioning. Fig. 2 also shows the ability of solar PV to significantly offset daytime air conditioning loads.

Table 3. Average ownership of cooling appliances

\begin{tabular}{|c|c|c|c|c|c|c|c|}
\hline \multirow{2}{*}{\multicolumn{2}{|c|}{$\begin{array}{l}\text { Number of appliances per } \\
\text { household }\end{array}$}} & \multicolumn{6}{|c|}{ Year } \\
\hline & & 2006 & 2011 & 2016 & 2021 & 2026 & 2031 \\
\hline \multirow[t]{3}{*}{ Rural India } & Fans & 0.64 & 0.96 & 1.39 & 1.86 & 2.23 & 2.45 \\
\hline & $\begin{array}{l}\text { Evaporative } \\
\text { coolers }\end{array}$ & 0.03 & 0.06 & 0.10 & 0.16 & 0.22 & 0.27 \\
\hline & $\begin{array}{l}\text { Air } \\
\text { conditioning }\end{array}$ & 0.00 & 0.00 & 0.01 & 0.01 & 0.02 & 0.04 \\
\hline \multirow[t]{3}{*}{ Urban India } & Fans & 1.65 & 2.06 & 2.58 & 3.11 & 3.63 & 3.91 \\
\hline & $\begin{array}{l}\text { Evaporative } \\
\text { coolers }\end{array}$ & 0.24 & 0.32 & 0.43 & 0.56 & 0.69 & 0.80 \\
\hline & $\begin{array}{l}\text { Air } \\
\text { conditioning }\end{array}$ & 0.02 & 0.05 & 0.09 & 0.16 & 0.24 & 0.30 \\
\hline UK & $\begin{array}{l}\text { Any cooling } \\
\text { technology }\end{array}$ & 0 & 0 & 0 & 0 & 0 & 0 \\
\hline
\end{tabular}




\section{Conclusions}

- Loughborough University’s high resolution stochastic domestic energy demand model has been expanded to model domestic electricity demand in India.

- The new version models Indian levels of appliance ownership for rural and urban households projected into the future.

- Ambient temperatures for India are modelled together with the option of air conditioning or other cooling technologies.

- Where present, air conditioning dominates electricity demand.

- Appliance ownership and therefore total electricity use in Indian households is predicted to remain lower than in the UK for the foreseeable future, with the exception of air conditioning loads.

- Due to the different proportions of appliance ownership, Indian household electricity demand has a relatively higher evening peak than UK households.

\section{Acknowledgements}

This study was funded by the Joint UK-India Clean Energy Centre (JUICE), a Newton Fund Project, EPSRC Reference EP/P003605/1.

\section{References}

1. Richardson I, Thomson M, Infield D. A high-resolution domestic building occupancy model for energy demand simulations. Energy Build. 2008;40(8):1560-6.

2. Richardson I, Thomson M, Infield D, Clifford C. Domestic electricity use: A high-resolution energy demand model. Energy Build. 2010;42:1878-87.

3. Richardson I, Thomson M. Integrated simulation of photovoltaic micro-generation and domestic electricity demand: A one-minute resolution open-source model. Proc Inst Mech Eng Part A J Power Energy. 2013;227(1):73-81.

4. McKenna E, Thomson M. High-resolution stochastic integrated thermal-electrical domestic demand model. Appl Energy [Internet]. 2016;165:445-61. Available from: https://dspace.lboro.ac.uk/dspacejspui/bitstream/2134/20103/3/McKenna\%2C 2016\%2C High-resolution stochastic integrated thermalelectrical domestic demand model.pdf

5. Barton JP. CREST Demand Model [Internet]. Loughborough University figshare database. 2018 [cited 2018 May 14]. p. 1. Available from: https:/figshare.com/s/6a1dc7f4b7fe851f1165

6. JUICE. Data Models [Internet]. Joint UK-India Clean Energy Centre. 2018 [cited 2018 May 14]. p. 1. Available from: http://www.juice-centre.org.uk/resources/models/

7. Rogers J. RESIDENTIAL CONSUMPTION OF ELECTRICITY IN INDIA DOCUMENTATION OF DATA AND METHODOLOGY Background Paper India: Strategies for Low Carbon Growth [Internet]. 2008. Available from: http://www.moef.nic.in/downloads/publicinformation/Residentialpowerconsumption.pdf

8. Sandwell P, Chambon C, Saraogi A, Chabenat A, Mazur M, Ekins-Daukes N, et al. Analysis of energy access and impact of modern energy sources in unelectrified villages in Uttar Pradesh. Energy Sustain Dev [Internet]. 2016 Dec [cited 2017 Jul 19];35:67-79. Available from: http://linkinghub.elsevier.com/retrieve/pii/S0973082616303398

9. Balance Of Systems. Our Projects. DENA RENEWABLE ENERGY SOLUTIONS PROGRAMME INDIA 2017 [Internet]. Balance of Storage Systems. 2017. p. 1. Available from: http://www.bosag.com/impact/our-projects 